\title{
BÀN VỀ PHÉP CHIẾU DÙNG CHO BẢN ĐỒ HIỆN TRẠNG SỦ DỤNG ĐẤT
}

\author{
TS. ĐÔNG TH!̣ BÍCH PHƯO'NG \\ Viện Khoa học Đo đạc và Bản đồ
}

\section{Tóm tắt:}

Bài báo làm rõ một số yếu tố ảnh hưởng đến việc lựa chọn phép chiếu dùng cho bản đồ hiện trạng sử dụng đất và đề xuất sử dụng phép chiếu hình trụ ngang đồng góc với k=0.9999, kinh tuyến trục địa phương cho bản đồ hiện trạng sử dụng đất từ cấp tỉnh trở xuống.

\section{Đặt vấn đề}

Lựa chọn phép chiếu bản đồ là giai đoạn quan trọng trong thiết kế bản đồ chuyên đề, tập bản đồ cũng như trong xây dựng quy định, quy phạm cho mỗi thể loại bản đồ. Để thống nhất công tác đo đạc và lập bản đồ trong phạm vi cả nước, từ năm 2001 Tổng cục Địa chính đã có Hướng dẫn áp dụng hệ quy chiếu và hệ tọa độ quốc gia VN-2000 [1], trong đó quy định áp dụng các lưới chiếu dùng cho bản đồ địa hình cơ bản, bản đồ hành chính, bản đồ địa chính. Tuy nhiên, đối với bản đồ chuyên đề, Thông tư 973 cho phép sử dụng các lưới chiếu khác phù hợp với mục đích thể hiện.

Đối với bản đồ hiện trạng sử dụng đất, Bộ Tài nguyên và Môi trường đã có quy định về lưới chiếu bản đồ [2] để đảm bảo tính thống nhất về cơ sở toán học, thuận lợi trong thành lập và sử dụng bản đồ, đặc biệt là khi sử dụng kết hợp với các bản đồ chuyên đề khác. Tuy nhiên với yêu cầu ngày một cao của công tác quản lý tài nguyên môi trường đối với dữ liệu không gian nói chung và bản đồ hiện trạng sử dụng đất nói riêng, các quy định về phép chiếu dùng cho bản đồ hiện trạng sử dụng đất đã trở nên không phù hợp xét từ một số khía cạnh.

\section{Lựa chọn phép chiếu cho bản đồ hiện trạng sử dụng đất}

Việc lựa chọn phép chiếu bản đồ phụ thuộc vào nhiều yếu tố. Trong các văn liệu bản đồ học thường phân loại các yếu tố cần phải cân nhắc mức độ ảnh hưởng khi lựa chọn phép chiếu cho một bản đồ cụ thể như sau:

1. Nhóm các yếu tố đặc trưng cho lãnh thổ cần lập bản đồ: vị trí địa lý, kích thước, hình dạng đường bao của lãnh thổ cần lập bản đồ...

2. Nhóm các yếu tố đặc trưng cho bản đồ cần thành lập: phương pháp sử dụng, mục đích sử dụng, tỷ lệ của bản đồ, nội dung, phương pháp thể hiện và các đòi hỏi về độ chính xác trong sử dụng bản đồ.

3. Nhóm các yếu tố đặc trưng cho phép chiếu như giá trị biến dạng, phân bố biến dạng, độ cong của lưới kinh vĩ tuyến...

Với sự phát triển của công nghệ số trong thành lập và sử dụng bản đồ, cần phải cân nhắc mức độ thông dụng của phép chiếu để đảm bảo điều kiện sử dụng bản đồ trong các phần mềm đồ họa và GIS thương mại. Phép chiếu của thể loại bản đồ có phạm vi sử dụng lớn như bản đồ địa hình, địa chính nên được lựa chọn trong một tập hợp phép 
chiếu, múi chiếu giới hạn để thuận tiện trong phối hợp sử dụng bản đồ. Đây có thể coi là nhóm các điều kiện ràng buộc trong lựa chọn phép chiếu (nhóm 4).

Bản đồ hiện trạng sử dụng đất tỷ lệ từ 1 : 25.000 đến 1:500.000 được [2] quy định thành lập ở lưới chiếu hình trụ ngang đồng góc với múi chiếu $6^{0}$, hệ số điều chỉnh biến dạng chiều dài $\mathrm{k}=0.9996$. Bản đồ tỷ lệ từ 1:10.000 đến 1:1.000 được thành lập với múi chiếu $3^{0}, \mathrm{k}=0.9999$. Bản đồ cấp xã được thành lập trong múi chiếu với kinh tuyến trục địa phương theo quy định của thông tư 973. Do tính chất sử dụng của bản đồ hiện trạng sử dụng đất, đối với việc lựa chọn phép chiếu yếu tố biến dạng diện tích - biên độ và phân bố- cần phải được quan tâm hàng đầu. Với vị trí và hình thể Việt Nam, có thể sử dụng một số phép chiếu đồng diện tích, ví dụ phép chiếu Bonn trong thành lập các bản đồ có yêu cầu cao về biến dạng diện tích. Hoặc, trong [4] có đề xuất phương án phép chiếu Chebyshev với biến dạng diện tích không vượt quá $0.05 \%$ trên toàn lãnh thổ Việt Nam. Tuy nhiên, xét đến các điều kiện nhóm 4, phép chiếu dùng cho bản đồ hiện trạng sử dụng đất chỉ nên được lựa chọn trong các phép chiếu họ UTM.

Dưới đây sẽ xem xét đặc điểm biến dạng diện tích của các phép chiếu họ UTM.

Công thức gần đúng để tính tỷ lệ diện tích của các phép chiếu họ UTM có dạng:

$$
p=\mu^{2}=k^{2}\left(1+\frac{\lambda^{2}}{2} \cos ^{2} \varphi\left(1+\eta^{2}\right)\right)^{2}
$$

với $\eta=e^{\prime} \cos \varphi$

Biến dạng diện tích (\%) được tính theo công thức:

$$
v_{p}=(p-1) .100
$$

\begin{tabular}{|c|c|c|c|c|c|c|c|}
\hline $\begin{array}{l}\left.\left.|\Delta \lambda|\right|^{\circ}\right) \\
\varphi\left({ }^{(}\right)\end{array}$ & 0 & 0.5 & 1 & 1.5 & 2 & 2.5 & 3 \\
\hline \multicolumn{8}{|c|}{$K=0.9999, V_{p}(\%)$} \\
\hline 24 & -0.020 & -0.014 & 0.005 & 0.037 & & & \\
\hline 20 & -0.020 & -0.013 & 0.007 & 0.041 & & & \\
\hline 16 & -0.020 & -0.013 & 0.008 & 0.043 & & & \\
\hline 12 & -0.020 & -0.013 & 0.009 & 0.046 & & & \\
\hline 8 & -0.020 & -0.013 & 0.010 & 0.047 & & & \\
\hline \multicolumn{8}{|c|}{$K=0.9996, V_{p}(\%)$} \\
\hline 24 & -0.080 & -0.074 & -0.055 & -0.023 & 0.022 & 0.079 & 0.149 \\
\hline 20 & -0.080 & -0.073 & -0.053 & -0.020 & 0.028 & 0.088 & 0.162 \\
\hline 16 & -0.080 & -0.073 & -0.052 & -0.017 & 0.033 & 0.096 & 0.173 \\
\hline 12 & -0.080 & -0.073 & -0.051 & -0.014 & 0.037 & 0.102 & 0.182 \\
\hline 8 & -0.080 & -0.073 & -0.050 & -0.013 & 0.039 & 0.107 & 0.189 \\
\hline
\end{tabular}

Bảng 1: Biến dạng diện tích phép chiếu UTM với $k=0.9999$ và $k=0.9996$ 
Bảng 1 trình bày kết quả xác định biến dạng diện tích $v_{p}$ trên phép chiếu UTM với $k=0.9999$ và $k=0.9996$.

Cũng có thể sử dụng công thức giản tiện hơn để xác định biến dạng diện tích trên các phép chiếu họ UTM. Cồng thức này thể hiện quan hệ giữa biến dạng diện tích và khoảng cách $\mathrm{y}_{\mathrm{m}}$ đến kinh tuyến trục.

Xuất phát từ công thức gần đúng để tính tỷ lệ chiều dài trong các phép chiếu họ UTM:

$$
\mu=k+\frac{y^{2}}{2 R^{2}}+\frac{y^{4}}{24 R^{4}}
$$

Bỏ qua thành phần $\frac{y^{4}}{R^{4}}$, tỷ lệ diện tích được xác định gần đúng theo công thức:

$$
p=k^{2}+k \frac{y^{2}}{R^{2}}
$$

Hoặc, đơn giản hơn $p=k^{2}+\frac{y^{2}}{R^{2}}$

Bảng 2 dưới đây trình bày quan hệ giữa biến dạng diện tích $v_{p}$ và khoảng cách đến kinh tuyến trục khi chuyển từ mặt phẳng phép chiếu UTM lên mặt ellipssoid. (Xem bảng 2)

Đối với múi $6^{0}$ (k=0.9996), các đối tượng nằm cách kinh tuyến trục dưới $180 \mathrm{~km}$ có biến dạng diện tích âm, tức là có diện tích trên bản đồ nhỏ hơn diện tích trên mặt ellipsoid. Các đối tượng nằm cách kinh tuyến trục trên $180 \mathrm{~km}$ có diện tích trên bản đồ lớn hơn diện tích trên mặt ellipsoid.
Đối với múi chiếu $3^{0}$ (k=0.9999) được sử dụng cho bản đồ địa hình tỷ lệ 1:10.000 và lớn hơn, cũng như hệ thống bản đồ địa chính, các đối tượng nằm cách kinh tuyến trục dưới $90 \mathrm{~km}$ có biến dạng âm về diện tích, tức là diện tích trên bản đồ nhỏ hơn diện tích trên mặt ellipssoid. Các đối tượng nằm cách kinh tuyến trục trên $90 \mathrm{~km}$ có diện tích trên bản đồ lớn hơn diện tích trên mặt ellipssoid. Các đối tượng nằm gần rìa múi có biến dạng diện tích $0.047 \%$ ở khu vực vĩ tuyến $8^{\circ}$ và $0.037 \%$ ở khu vực vĩ tuyến $24^{\circ}$. Các đối tượng nằm trong vùng từ $60 \mathrm{~km}$ đến $110 \mathrm{~km}$ tính từ kinh tuyến trục có biến dạng diện tích dưới $0.01 \%$.

Quy định kinh tuyến trục các múi chiếu địa phương của thông tư 973 đảm bảo phần lớn diện tích mỗi tỉnh nằm trong vùng có biến dạng độ dài và diện tích nhỏ nhất (cách kinh tuyến trục từ 60 đến $110 \mathrm{~km}$ ). Với các tỉnh có $\Delta \lambda \approx 2^{0}$ (Nghệ An, Thanh Hóa), việc lựa chọn kinh tuyến trục đã ưu tiên vùng ven biển, nơi tập trung dân cư nằm trong khu vực có biến dạng thấp nhất, ngoài ra cũng ưu tiên chọn kinh tuyến trục trùng với kinh tuyến trục bản đồ địa hình tỷ lệ 1:10.000 và lớn hơn để tránh các khác biệt giữa hệ thống bản đồ địa hình và hệ thống bản đồ địa chính. Mặc dù biến dạng về diện tích do phép chiếu là tương đối nhỏ, tuy nhiên với phương án thống nhất phép chiếu của hệ thống bản đồ địa hình và bản đồ địa chính tỷ lệ lớn được một số tác giả đề xuất gần đây, bản đồ địa chính của cùng một tỉnh, thậm chí cùng một xã có thể phải thành lập ở hai múi chiếu. Ngoài ra, một số khu vực

Bảng 2: Biến dạng diện tích theo khoảng cách đến kinh tuyến trục

\begin{tabular}{|c|c|c|c|c|c|c|c|c|c|}
\hline $\mathrm{y}(\mathrm{km})$ & 0 & 55 & 90 & 110 & 165 & 180 & 220 & 250 & 330 \\
\hline $\mathrm{k}=0.9999, \mathrm{v}_{\mathrm{p}}(\%)$ & -0.020 & -0.013 & 0 & 0.010 & 0.047 & & & & \\
\hline $\mathrm{k}=0.9996, \mathrm{v}_{\mathrm{p}}(\%)$ & -0.080 & -0.073 & -0.06 & -0.050 & -0.013 & 0 & 0.039 & 0.106 & 0.188 \\
\hline $\mathrm{k}=1.0000, \mathrm{v}_{\mathrm{p}}(\%)$ & 0.000 & 0.007 & 0.020 & 0.030 & 0.067 & 0.080 & 0.119 & 0.186 & 0.268 \\
\hline
\end{tabular}


sẽ phải chịu biến dạng diện tích lên tới $0.047 \%$.

Kết quả tính toán ở bảng 2 cho thấy, đối với các khu vực có $\Delta \lambda \leq 2^{0}$, phép chiếu UTM với k=1 (phép chiếu Gauss-Kruger) có phân bố biến dạng diện tích tốt hơn. Với kinh tuyến trục nằm tại khu vực trung tâm, không tỉnh nào có khoảng cách đến kinh tuyến trục vượt quá $110 \mathrm{~km}$. Như vậy phép chiếu UTM với $\mathrm{k}=1$ có biến dạng diện tích trong phạm vi mỗi tỉnh biến thiên từ $0 \%$ dọc kinh tuyến trục đến $0.03 \%$ ở các khu vực cực đông và cực tây, không có biến dạng âm. Trong khi đó phép chiếu UTM với k=0.9999 được sử dụng cho bản đồ địa chính và bản đồ HTSDĐ tỷ lệ 1:10.000 và lớn hơn hiện nay có biến dạng diện tích biến thiên từ $-0.02 \%$ đến $0.028 \%$ (Lâm Đồng, Bình Dương, Bà Rịa - Vũng Tàu). Mặc dù vậy, việc thay đổi các quy định về phép chiếu bản đồ địa chính có thể gây những xáo trộn không cần thiết. Trong khi đó, bản đồ hiện trạng sử dụng đất được thành lập định kỳ năm năm một lần rất cần có những quy định được sửa đổi phù hợp với sự phát triển của công nghệ và đòi hỏi thực tiễn.

Theo Quy định 2007 về lựa chọn tỷ lệ bản đồ cần thành lập theo quy mô diện tích tự nhiên và cấp hành chính, thì đa số bản đồ hiện trang sử dụng đất cấp xã sẽ được thành lập ở tỷ lệ 1:10.000 hoặc lớn hơn, và đa số bản đồ cấp huyện, tỉnh sẽ được thành lập ở tỷ lệ từ 1:25.000 đến 1:100.000.

Như vậy, bản đồ HTSDĐ cấp huyện, tỉnh được thành lập với các múi chiếu $6^{\circ}$, k=0.9996 theo quy định của Thông tư 973, tức là múi chiếu dùng cho hệ thống bản đồ địa hình với các kinh tuyến trục $105^{\circ}$ và $111^{\circ}$. Bản đồ HTSDĐ cấp huyện, tỉnh với cơ sở toán học như vậy thuận tiện khi sử dụng kết hợp với các bản đồ địa hình, bản đồ chuyên đề khác. Tuy nhiên, như đã phân tích ở trên, một số khu vực ở rìa múi chiếu, tức là dọc kinh tuyến $108^{\circ}$ sẽ phải chịu biến dạng diện tích lên đến $0.19 \%$ (diện tích trên bản đồ lớn hơn diện tích trên mặt ellipsoid), trong khi rất nhiều khu vực nằm dọc kinh tuyến trục $105^{0}$ chịu biến dạng - 0.08\% (diện tích trên bản đồ nhỏ hơn diện tích thực).

Một số tỉnh nằm dọc kinh tuyến $108^{\circ}$ sẽ phải thành lập bản đồ trên hai múi chiếu. Với phương án mở rộng múi chiếu, một số khu vực trên bản đồ tỷ lệ 1:25.000 sẽ phải chịu biến dạng diện tích lên đến $0.34 \%$ (Quảng Nam, Lâm Đồng) (xem bảng 3).

Ngoài ra, việc tổng hợp bản đồ cấp huyện từ bản đồ cấp xã, cũng như kết hợp sử dụng bản đồ các cấp sẽ tương đối khó khăn, do có sự khác biệt đôi khi là hoàn toàn về tọa độ vuông góc giữa bản đồ tỷ lệ 1:10.000 (đa số bản đồ cấp xã) và bản đồ tỷ lệ 1:25.000 (đa số bản đồ cấp huyện). Biến dạng chiều dài và diện tích cũng sẽ gây khó khăn cho thành lập và sử dụng bản đồ ở địa phương. (Xem bảng 3)

Với phương án được một số địa phương lựa chọn trong thành lập bản đồ HTSDĐ cấp huyện và cấp tỉnh, cũng là quy định cho thành lập một số loại bản đồ chuyên đề [3] sử dụng phép chiếu với k=0.9996, kinh tuyến trục địa phương cho các bản đồ tỷ lệ 1:25.000 và nhỏ hơn, các ưu điểm của lựa chọn kinh tuyến trục cho từng địa phương theo Thông tư 973 hoàn toàn mất tác dụng. Đó là do phép chiếu UTM với k=0.9999 cho biến dạng nhỏ nhất về cả chiều dài lẫn diện tích ở khu vực từ 60 đến 110 km cách kinh tuyến trục, còn phép chiếu với k=0.9996 ở vùng từ 150 đến $170 \mathrm{~km}$ cách kinh tuyến trục có biến dạng tối ưu. Trong khi đó, với kinh tuyến trục theo Thông tư 973, không tỉnh nào có khoảng cách đến kinh tuyến trục quá $140 \mathrm{~km}$.

Do các tỉnh của Việt Nam có chiều rộng theo phương vĩ tuyến không lớn ( $\Delta \lambda_{\max }=1.93^{\circ}$ tại Nghệ $\left.A n\right)$, với lựa chọn kinh tuyến trục địa phương theo Thông tư 
Bảng 3: Các tỉnh nằm trên hai múi chiếu $6^{0}$ và biến dạng diện tích tối đa cho phương án múi $6^{\circ}$ mở rộng

\begin{tabular}{|c|c|c|c|c|c|}
\hline Tỉnh & $\lambda_{\min }$ & $\lambda_{\max }$ & kinh tuyến trục & $\begin{array}{c}y_{\max } \\
(\mathrm{km})\end{array}$ & $\begin{array}{c}V_{p \max } \\
(\%)\end{array}$ \\
\hline Quảng Ninh & 106.43522 & 108.0991 & 105 & 341 & 0.206 \\
\hline TT Huế & 107.01250 & 108.2034 & 105 & 352 & 0.226 \\
\hline Đà Nẵng & 107.81478 & 108.3409 & 105 & 367 & 0.252 \\
\hline Quảng Nam & 107.20144 & 108.7506 & 105 & 413 & 0.339 \\
\hline Bình Thuận & 107.39034 & 108.9842 & 111 & 397 & 0.308 \\
\hline Kon Tum & 107.32887 & 108.5607 & 105 & 392 & 0.298 \\
\hline Gia Lai & 107.44276 & 108.8953 & 111 & 391 & 0.297 \\
\hline Đắk Lắk & 107.47673 & 109.0067 & 111 & 388 & 0.290 \\
\hline Đắk Nông & 107.20198 & 108.1241 & 105 & 344 & 0.211 \\
\hline Lâm Đồng & 107.26224 & 108.7311 & 105 & 410 & 0.335 \\
\hline
\end{tabular}

973 và $\mathrm{k}=0.9999$, các tỉnh nằm trọn trong vùng có biến dạng và diện tích nhỏ. Ngoại trừ biến dạng diện tích tối đa $(0.035 \%)$ có mặt dọc kinh tuyến $107^{\circ}$ tại khu vực cực đông huyện Cát Hải tỉnh Hải Phòng, bản đồ hiện trạng sử dụng đất tất cả các tỉnh, nếu được thành lập tại múi chiếu UTM với $\mathrm{k}=0.9999$ và kinh tuyến trục địa phương đều có biến dạng diện tích nằm trong khoảng từ $-0.02 \%$ đển $0.028 \%$ (tỉnh Lâm Đồng). Ngoài ra, phương án này đảm bảo sự thống nhất về cơ sở toán học của hệ thống bản đồ địa chính, hiện trạng và quy hoạch trong phạm vi từng tỉnh, thuận lợi trong thành lập bản đồ hiện trạng và quy hoạch từ bản đồ địa chính cũng như trong sử dụng bản đồ cho công tác quản lý đất đai ở địa phương. Đây cũng là lựa chọn của nhiều địa phương để thành lập bản đồ HTSDĐ trong kỳ Tổng kiểm kê, thống kê đất đai 2010 vừa qua.
Đối với các bản đồ chuyên đề được thành lập trong pham vi đơn vị hành chính cấp tỉnh vùng địa lý, phương án sử dụng phép chiếu UTM với $k=0.9999$, kinh tuyến trục địa phương cũng có phân bố biến dạng tốt hơn cả về độ dài và diện tích so với phương án được một số địa phương và đơn vị áp dụng (phép chiếu UTM với k=0.9996, kinh tuyến trục địa phương cho bản đồ chuyên đề tỷ lệ 1:25.000 và nhỏ hơn).

\section{Kết luận}

1. Trong lựa chọn phép chiếu cho bản đồ hiện trạng sử dụng đất cần xem xét các yếu tố như mức độ thông dụng của phép chiếu để đảm bảo điều kiện sử dụng trong các phần mềm thương mại và phối hợp với các bản đồ chuyên đề khác. 